\title{
O CUIDADO HUMANO DIANTE DA TRANSIÇÃO AO PAPEL MATERNO: VIVÊNCIAS NO PUERPÉRIO
}

\author{
HUMAN CARE FACING TRANSITION TO MATERNAL ROLE: PUERPERAL EXPERIENCES
}

EL CUIDADO HUMANO FRENTE A LA TRANSICIÓN HACIA EL ROL MATERNO: VIVENCIAS EN EL PUERPE$R I O$

\section{Ivete Palmira Sanson ZAGONEL ${ }^{1}$ Marialda MARTINS ${ }^{2}$ Karen Fabiana PEREIRA ${ }^{3}$ Juliana ATHAYDE ${ }^{4}$}

\begin{abstract}
RESUMO: Discorre sobre as modificações que a transição ao papel materno suscitam no período de puerpério. Como objetivos buscou-se, desvelar como a mulher puérpera vivencia a transição ao papel materno, ao mesmo tempo em que é prestado o cuidado; estabelecer caminhos metodológicos de implementação de novos modelos de cuidado humano, que privilegiem a mudança de papéis. Estudo qualitativo, dentro da trajetória metodológica de pesquisa-cuidado. Foram entrevistadas treze puérperas, primigestas, independentemente da idade. Aplicou-se entrevista semi-estruturada em ambulatório. A análise iniciou através de leitura e re-leitura das informações. Através de exercício intelectual foram estruturadas unidades de significado tornando o processo de análise mais minucioso, atingindo a profundidade da compreensão. Obtiveram-se três categorias. Apontam para a necessidade do enfermeiro estar alerta para os sinais indicativos da vivência da transição, enfatizando o apoio profissional suportivo diante das múltiplas possibilidades do ser.
\end{abstract}

PALAVRAS CHAVES: Transição, puerpério, cuidado de enfermagem

ABSTRACT: It is a study on the changes the transition to maternal role brings about in the puerperal period. It objectified to uncover how the puerperal mother experiences transition to maternal role while care is delivered; to set up new methodological ways to implement new human care models privileging role change. It's a qualitative study trailing a methodological research-care trajectory. Thirteen puerperal, several-aged primíparas were interviewed. The instrument used was a semi-structured interview in the clinic. Analysis was effected by information reading and re-reading. To become the analysis process more accurate reaching depth in understanding, meaning units were structured through intellectual exercise. Three categories take up the apprehended. Point out the need for nurses to be alert for the signs of transition, stressing supportive professional help facing the multiple possibilities of being.

KEYWORDS: transition, puerperium, nursing care

RESUMEN: Discurre sobre las modificaciones que la transición hacia el rol materno suscitan en el período del puerperio. Como objetivos se busco, desvelar como la mujer puérpera vivencia la transición al papel materno, al mismo tiempo en que es prestado el cuidado; estabelecer caminos metodológicos de implementación de nuevos modelos de cuidado humano, que privilegien el cambio de roles. Estudio cualitativo, dentro de la trayectoria metodológica de búsqueda-cuidado. Fueron entrevistadas trece puérperas, primigestas, independientemente de la edad. Se aplico la entrevista semi-estructurada en ambulatorio. El análisis se inicio através de la lectura y re-lectura de las informaciones. Através del ejercício intelectual fueron estructuradas unidades de significado volviendo el proceso de análisis mas minucioso, apuntando a la profundidad de la comprensión. Se obtuvo las categorías: Percepciones y sentimientos de la transición a la maternidad. Apoyo de soporte en la fase de transición puerperal. Dificultades que la transición suscita. Apuntan para a que el enfermero este alerta para las señales indicativas de la vivencia de la transición, enfatizando el apoyo profesional de soporte frente a las múltiples posibilidades del ser.

PALABRAS CLAVES: Transición, puerpério, cuidado de enfermería

\section{INTRODUÇÃO}

A transição à maternidade / paternidade é freqüentemente descrita como uma época de desordem e desequilíbrio, bem como de satisfação para as mães e os parceiros (EDWARDS, 2002). O início da adaptação à maternidade suscita nos pais sentimentos de incapacidade, confusão frente às novas demandas, levando a buscar apoio

1.Enfermeira. Professora Adjunto do Curso de Enfermagem da UFPR. Doutora em Enfermagem, área de concentração: Filosofia da Enfermagem. Coordenadora do NEPECHE/UFPR (Núcleo de Estudos, Pesquisa e Extensão em Cuidado Humano de Enfermagem). e-mail: ivetesanzag@yahoo.com.br

2. Enfermeira. Professora Assistente do Curso de Enfermagem da UFPR. Mestre em Enfermagem. Área de atuação Materno-Infantil. Membro do NEPECHE/UFPR.

3. Acadêmica de Enfermagem do $9^{\circ}$ período. Membro do NEPECHE/UFPR.

4. Acadêmica de Enfermagem do $10^{\circ}$ período. Membro do NEPECHE/UFPR. Bolsista PIBIC. 
um no outro. As mães ocupadas com o cuidado ao filho nem sempre conseguem oferecer o apoio necessário ao pai, o qual sente-se privado de suporte. O despreparo em lidar com as emoções e cuidados exigidos neste período, conduz à inadequação no desempenho de papel, porém à medida que vivenciam esta experiência a inabilidade vai desaparecendo e emerge sentimentos de companheirismo, compartilhamento de situações e entrega aos papéis exteriorizados através do amor, carinho, afeto, solidariedade entre os pais.

A transição à maternidade / paternidade é uma transição desenvolvimental, uma crise de desenvolvimento, conforme salienta Demickm, Bursik e Dibiase apud STETSON (2002, p.445), "no ponto de crise, ocorre um momento no qual a pessoa está mental e fisicamente preparada, a cultura empurrando e a pessoa tentando alcançar alguma mudança no desenvolvimento. Devido a isso a pessoa está motivada para a mudança... Os pais estão estimulados a tentar novas estratégias de enfrentamento, esforçando-se para dominar seus novos papéis e para atingir novos níveis de desenvolvimento".

O desempenho dos novos papéis frente à maternidade/paternidade exige a adaptação ao novo ser, ao filho que nasceu, conciliando a criança real com aquela fantasiada, sonhada, durante todo o período gestacional. Os pais ficam surpresos diante do aspecto do filho, a aparência física, a qual difere da idealizada, levando a uma maior dificuldade na aceitação imediata. $O$ vínculo pais-filho ocorre gradativamente à medida que as incertezas, angústias, decepções vão se dissipando e torna-se mais intenso quando conseguem superar o conflito interno com relação às dificuldades de envolvimento.

O desempenho e adaptação ao papel materno/paterno também estão envoltos pelo aspecto cultural da família ou sociedade em que vivem. O envolvimento do marido, parceiro, mãe, sogra e mesmo dos profissionais de saúde com a nova mãe pode significar apoio ou indicar o quanto a mãe está inapta em realizar os cuidados de si e do filho. Assim, é importante oferecer orientações nesta fase, de forma gradativa, aos poucos, percebendo onde há maior precariedade de informações e então, dialogar, estimulando a auto-estima e aprendizado de forma motivadora, construtiva.

Com relação à adaptação materna diante do novo papel EDWARDS (2002, p.466) evidencia três fases evidentes neste período, a fase dependente, a fase dependente-independente e a fase interdependente. As características da fase dependente estão relacionadas à habilidade de adaptarse, o que leva em média vinte e quatro horas ou até dois dias, cujo enfoque é em si mesma e no preenchimento das necessidades básicas de conforto, repouso, proximidade e nutrição do filho; constitui um período de grande excitação em que necessita explicitar a experiência da gestação e parto.

A segunda fase dependenteindependente inicia no segundo ou terceiro dia e dura de dez dias a várias semanas. $O$ enfoque está no cuidado do bebê e competência em desempenhar ou direcionar este cuidado. Esta fase caracteriza-se ainda, no assumir,comportamento que é facilitado através da preparação ao parto, controle da dor obstétrica, contato precoce com o filho, alojamento conjunto e alta precoce. Tem necessidade de aceitação, ânsia em aprender e praticar - período ideal para orientações - lida com desconfortos físicos, mudanças emocionais e pode experienciar melancolia.

As preocupações emocionais são mais comuns nas mães abatidas, tensas, irritáveis e deprimidas. A fadiga afeta vários aspectos de sua vida, entre eles as relações com o marido ou membros da família e as responsabilidades domésticas. Esta fase é freqüentemente caracterizada pela melancolia pós-parto ocorre em até $80 \%$ das muIheres. A instabilidade costuma atingir o pico em torno do quinto dia, diminuindo no décimo dia. Os fatores bioquímicos, psicológicos, sociais e culturais tem sido apontados como possíveis causas para o estado depressivo pós-parto. Nesse sentido, EDWARDS (2002, p.468) afirma que "o pósparto mostra-se um período de vulnerabili- 
dade emocional e física para as novas mães que podem estar psicologicamente sobrecarregadas com a responsabilidade".

A fase interdependente concretizase quando a mãe e sua família movimentam-se sob a forma de uma unidade, como membros em interação, ocorre a reafirmação do relacionamento com o companheiro, retomada da atividade sexual e resolução dos papéis individuais. A intimidade sexual favorece o aspecto adulto da família. Um esforço especial constante deve ser desenvolvido para fortalecer o relacionamento de adulto para adulto como base para a unidade familiar.

O movimento estabelece-se envolvendo toda a família com a chegada de um novo membro, o qual inicia-se com o nascimento e prossegue no domicílio. Para Sank apud EDWARDS (2002, p.457) "a paternidade/maternidade constitui um processo de aquisição e de transição de papel iniciado na gestação. A transição acaba quando os pais desenvolvem a sensação de conforto e de confiança no desempenho do papel de pais. O processo tem dois componentes. O primeiro envolve o conhecimento e a habilidade nas atividades de cuidado do bebê e o segundo, abrange a valorização e o conforto, a atitude de carinho, a conscientização e a preocupação com as necessidades e com os desejos do bebê".

A transição como forma ameaçadora ao ser humano representa um obstáculo aos objetivos de vida, interrompe fases ou as sobrepõe. A transição suscita a crise, a qual surge como resposta aos eventos geradores de mudanças, seja no contexto individual, familiar ou social. DAL SASSO (1994, p.56-57) explicita que "o que faz surgir uma situação de crise no ser humano não é meramente a exacerbação de uma causa específica, mas principalmente uma combinação de sentimentos, reações e significados ao momento que está sendo vivenciado".

$\mathrm{Na}$ mesma linha de pensamento situa-se KONIAK-GRIFFIN (1993) ao afirmar que as atividades de promoção à saúde começam no pré-natal, desde os estágios iniciais, mediante orientação antecipatória com relação à transição de papel e ensino efetivo e comportamental das habilidades maternas, facilitando, assim, o alcance do papel materno.

A adaptação ao papel materno pode ser difícil a muitas mulheres pela carência de clareza às especificidades do papel materno. O papel de mãe é um produto da cultura e refere-se a ações que se espera que a mãe desempenhe em relação a seu filho. A autora explicita que "o alcance de uma identidade materna é caracterizado pelo experienciar da mãe de um sentido de equilíbrio interno, confiança e competência no seu desempenho de papel" (p.258). A formação de uma identidade materna é hipotetizada por tomar lugar concomitantemente à internalização de papel.

Após discorrer sobre as modificações que a transição ao papel materno vivenciadas no período de puerpério suscitam, passamos a expor os objetivos deste estudo. Desvelar como a mulher puérpera vivencia a transição ao papel materno ao mesmo tempo em que é prestado o cuidado; estabelecer caminhos metodológicos de implementação de novos modelos de cuidado humano, que privilegiem a mudança de papéis.

\section{CAMINHO METODOLÓGICO}

Estudo qualitativo, dentro da trajetória metodológica de pesquisa-cuidado conforme preconiza ARRUDA e ZAGONEL (1997), buscando desvelar como se estabelece a transição ao papel materno ao mesmo tempo em que é prestado o cuidado. Ao desvelar o significado dessa vivência é possível implementar um modelo de cuidado voltado às reais necessidades da cliente/familiar, inovando através da implementação de novas tecnologias de cuidado e, portanto, delineando um modelo adequado a esta realidade da mulher.

O pesquisar-cuidar não se constitui em entidade metodológica isolada, separada, pois ao mesmo tempo em que o pesquisador está apreendendo o significado da experiência, está cuidando. A pesquisacuidado tem a preocupação com a inter- 
relação dos conceitos da metodologia e do cuidado simultaneamente. Esta abordagem não visa apenas ativar o desvelamento e as descobertas através do método, mas é um acender a luz dentro de nosso ser e do outro, percebendo a essência de estar e serno-mundo.

LEONARD (1989) afirma que somos seres engajados e constituídos por nossa compreensão interpretativa das situações significativas. Para obter essa compreensão interpretativa nós, enquanto seres, utilizamos nossas tradições lingüísticas e culturais conseguindo, assim, perceber os fatos do mundo mediante uma interpretação baseada em nosso referencial. Os sujeitos do estudo foram as mulheres puérperas, primigestas, independentemente da idade, as quais estavam vivenciando o período puerperal, a nível ambulatorial, atendidas na consulta de enfermagem de puerpério.

\section{COLETA DAS INFORMAÇÕES}

A coleta de informações foi obtida através da aplicação na realidade ambulatorial de uma maternidade de Curitiba, de instrumento dirigido à mulher puérpera, na modalidade de entrevista semi-estruturada, obtida diretamente entre pesquisadorcliente, quando do retorno da puérpera para a consulta de enfermagem com aproximadamente dez dias de pós-parto. A proposta de pesquisa foi aprovada pelo Comitê de Ética da Instituição. O instrumento contemplou dados pessoais, obstétricos e aqueles relacionados à transição, com questões que conduzem à temática pesquisada. A entrevista envolve um processo informal e interativo entre pesquisadora-cuidadora e cliente. Nesta modalidade de pesquisa não há a preocupação com o número de sujeitos entrevistados, mas com a qualidade dos depoimentos de cada participante. Os depoimentos obtidos não se esgotam, são perspectivais, a cada olhar surge um novo olhar. As entrevistas foram gravadas após consentimento esclarecido e assinado pelos sujeitos, os quais foram informados sobre a participação expontânea, que o anonimato das informantes seria garantido, assim como permitida sua desistência em participar. Foram entrevistadas treze mulheres puérperas, primigestas, independentemente de idade. A opção por primigestas deu-se pela característica de ser a primeira vez que experiência a transição à maternidade, possibilitando captar o sentido de tal vivência. Foi obtido o consentimento da instituição através do Comitê de Ética, bem como o consentimento livre e esclarecido de cada cliente entrevistada. Tomou-se o cuidado de preservar todos os aspectos éticos que permeiam a pesquisa com seres humanos e esclarecer a cada sujeito sobre a liberdade em participar, anonimato das informações, propósitos da pesquisa e formas de coleta das informações.

\section{ANÁLISE DOS DEPOIMENTOS}

A análise qualitativa iniciou percorrendo etapas de leitura e re-leitura das informações, apreendendo o sentido da vivência da transição ao papel materno. Através de exercício intelectual foram estruturadas unidades de significado tornando o processo de análise mais minucioso, atingindo a profundidade da compreensão. Como se trata de modalidade de pesquisa-cuidado, à medida que as informações eram coletadas, o cuidado era prestado de acordo com as demandas e necessidades indicadas pelas puérperas.

$\mathrm{Na}$ amostra de 13 puérperas, 4 $(30,77 \%)$ eram adolescentes, com idade entre 15 a 18 anos, $8(61,54 \%)$ incluídas na faixa etária de 20 a 28 anos e 1 (7,69\%) com 35 anos. Todas são primigestas. Entre as puérperas $5(38,46 \%)$ são casadas, 4 $(30,77 \%)$ vivem em união consensual e 4 $(30,77 \%)$ são solteiras. A idade dos companheiros variou de 19 a 30 anos. O grau de instrução prevalente é o ensino fundamental com $8(61,54 \%)$ clientes e ensino médio com $5(38,46 \%)$ clientes. Entre as treze puérperas, $6(46,15 \%)$ não tem ocupação, 2 $(15,40 \%)$ são estudantes e as demais tem ocupação variando entre balconista, auxiliar de escritório, garçonete, vendedora e babá. A ocupação do companheiro é diversificada ocorrendo maior incidência nas funções de 
servente e vendedor com 2 em cada indicação $(36,36 \%) ; 1$ (9,1\%) está desempregado. As demais se situam em pintor, padeiro, soldador, produtor cenográfico, motoboy, auxiliar administrativo. Não são apontadas as ocupações de 2 companheiros pelas puérperas, quando solteiras. Entre as treze clientes entrevistadas, $4(30,77 \%)$ tem renda familiar de 300,00 a 500,$00 ; 3(23,08 \%)$ entre 600,00 e 800,$00 ; 3(23,08 \%)$ entre 900,00 e 1.100,00; e 3 (23,08\%) não tem nenhuma renda, vivem da ajuda de familiares ou vizinhos. Todas realizaram pré-natal com o número de consultas acima de seis. O parto normal obteve maior prevalência, ocorrendo com $8(61,54 \%)$ clientes e cesárea em $5(38,46 \%)$.

Pela análise qualitativa, foi possível apreender o sentido da vivência, bem como a explicitação da transição ao papel materno, através de três categorias selecionadas a partir dos depoimentos expressos pelas puérperas: Percepções e sentimentos da transição à maternidade; Apoio suportivo na fase de transição puerperal; Dificuldades que a transição suscita. A letra após o depoimento indica $D$-discurso e o número 1 , como sendo da primeira cliente entrevista$\mathrm{da}$, e assim sucessivamente.

Ao analisar a primeira categoria "percepções e sentimentos da transição à maternidade" entre as adolescentes, foi possível apreender a simultaneidade de sentimentos vivenciados, os quais se misturam com satisfação e acúmulo de encargos pelos diferentes papéis assumidos, impedindo de realizar atividades que antes da gravidez conseguiam fazer. A falta de convívio social, horas de sono, dedicação exclusiva ao filho, torna a experiência diferenciada, porém prazerosa.

Independente da idade, a transição à maternidade pode ser imprevisível, estressante e modificar a autoconfiança da mãe no cuidado do filho. A transição à maternidade pode ser descrita conforme pontuam MC VEIGH e SMITH (2000, p.270) "como um rito de passagem e entrada à idade adulta. Tornando-se mãe adolescente, a jovem automaticamente, interromperá seus planos de vida e segundo as mesmas auto- ras, são menos motivadas a freqüentar cursos de pré-natal, a ter relacionamentos estáveis, recebe menos suporte social e aceitam menos sua gravidez. As mães adolescentes apresentam maior dificuldade para compreender as alterações comportamentais do bebê e são menos motivadas ao aleitamento materno." Os depoimentos confirmam:

"São muitas mudanças, eu queria tê o nenê, daí eu engravidei e veio... Não durmo mais direito. Estou feliz, bem feliz" (D1-15 anos).

"O que mudou, é que tem que ter mais responsabilidade... tipo, tenho que cuidar de mim, dele... eu saia bastante, agora tenho que ficar mais com ele. Mas, estou muito alegre, eu queria ter um filho" (D2-16 anos).

"Foram muitas mudanças que aconteceu... deixei de fazer muita coisa, como sair, dormir direito. É bem diferente. Quando ainda tá na barriga é uma coisa diferente, mas agora, já tá com a criança do lado aumenta o afeto. Eu tô muito feliz" (D3-17 anos).

"O que mudou é que agora eu tô com minha filha aí do lado. Agora eu só cuido, cuido, cuido e não durmo mais. Não tem como explicar, é muito diferente, é ótimo. Valeu a pena todo o sacrifício, como ter apanhado durante a gravidez" (D4-18 anos).

Entre as mães não adolescentes, percebe-se que há maior envolvimento com o bebê, relacionando o cuidado como dependência a sua total dedicação, o que difere dos depoimentos das adolescentes. Assim, pode-se inferir que a idade interfere na adaptação ao papel materno, denotando maior responsabilidade e envolvimento sem a conotação de renúncia das tarefas que realizava antes da ocorrência da gravidez. A transição à maternidade estabelece-se apenas com a ocorrência do nascimento, porém quando a esta, acrescenta-se a transição de saúde-doença pelo nascimento do filho com problemas respiratórios ou outros, a transição ocorre com impacto maior às mães e familiares. Ter um filho pela primeira vez e 
este permanecer na unidade neonatal, separando mãe-filho, suscita sentimentos de infelicidade, preocupação, ansiedade, medo, angústia pelo prognóstico desconhecido. Prematuridade ou doença podem dificultar a capacidade de interação dos pais com o bebê, influenciando na emissão de mensagens que signifiquem sinais de comunicação entre pais e recém-nascido, necessitando um cuidado adicional, empatia e apoio emocional, com ênfase nas intervenções individualizadas e de comunicação.

Nos casos em que a mãe tem alta hospitalar e o bebê permanece internado, as ansiedades da mãe e familiares são muito grandes. A vontade de estar sempre com o bebê, amamentá-lo e o desconforto de ficar longe do lar um tempo considerável do dia desorganizam a vida emocional da nova mãe, como salientam ELZIRIK et al (2001). $A$ atitude da mulher como mãe depende de vários fatores, seu desenvolvimento, a identificação com a própria mãe, a aceitação do seu papel feminino e de mãe e suas experiências pessoais, o que pode ser observado pelos depoimentos.

"Quando você entra no hospital ainda não tem o nenê, quando você vai para casa com ele, tudo é diferente. Tem que se preocupá, tem que cuidá, você tá comendo tem que largá, tá dormindo tem que acordá porque o nenê começa a chorar. Você quer fazer alguma coisa, não pode, porque tem que cuidar do nenê. Mas... é tão bonitinho... Mudou tudo na minha vida, tudo, tudo, tudo. Tudo para melhor. Tirando a correria de não comer direito, as dores, é bom ser mãe. Estou feliz. É bom saber que tem uma pessoa que depende só de mim, que só eu posso cuidar, eu que dou mamá, ela depende só de mim" (D5-20 anos).

"O bebê toma todo o tempo, você fica ali só se dedicando, mas a gente fica mais alegre, essas coisas. Eu sinto alegria" (D6-20 anos).

"As mudanças com o nenê foram mais no lado emocional, agora eu tenho alguém para me preocupar, de- pende de mim. Estou satisfeita, só quero ficar perto dela" (D7-21 anos).

"Eu acho que nem mudei, se mudei foi coisa boa. Estou me sentindo muito bem" (D8-24 anos).

"As mudanças foi bem pra melhor, porque eu era sozinha. À noite você muda o horário de dormir, é choro, tem que dar mamá. Mas é bom, não reclamo não. É uma coisa muito boa, é uma coisa diferente, eu não consigo explicar. É muito bom ser mãe" (D9-28 anos).

"Eu estou preocupada com ela. Agora eu fico um pouco triste que eu não posso ir lá dentro na neo. Fico feliz, dá uma emoção, mas na mesma hora eu tô triste. Agora ela depende só de mim"(D10-35 anos).

"No começo eu tinha um pouco de receio, como eu ia ajudar ela nascer, né. Mas, daí eu vi realmente, que não é aquela coisa, que é uma coisa que realmente você ajuda. Você tá num parto normal, você sente dor, mas aquela dor que vem e vai, né, uma dor de vida. Eu me sinto segura no cuidado com ela, como eu imaginava que seria. Agora sou mais feliz, sou mais forte, mais segura, sei mais o que fazer, digamos, sou mais decidida" (D13-22 anos).

A análise da segunda categoria "apoio suportivo na fase de transição puerperal', demonstra ser de extrema importância a presença de familiar ou significante para auxiliar nas ações domésticas e mesmo com o cuidado do bebê. Percebe-se entre as adolescentes que citam a mãe, sogra, marido, cunhadas, que contam com apoio físico, não ocorrendo maior envolvimento emocional para compreender seus sentimentos e poder conversar sobre este período. BRANDEN (2000) enfatiza que a cliente deve ser estimulada a expressar seus sentimentos em torno dessa experiência, avaliando todas os progressos pelo estágio de adaptação materna, incluindo o estado emocional e quaisquer sinais de depressão puerperal. É importante auxiliar a 
desenvolver estratégias de enfrentamento das dificuldades, através da oportunidade de expressar seus sentimentos. A ajuda financeira necessária nessa fase, também é enfatizada, uma vez que a falta de condições dificulta atender todas as demandas do bebê e da própria puérpera. Pela pouca idade, ao assumir o papel materno, exteriorizam medo do futuro, insegurança do local para morar, a vivência solitária sem o companheiro, o desamor da família ao julgar a gestação nessa idade como um ato errôneo, falta de diálogo. As puérperas adolescentes impõem desafios especiais, inicialmente entendendo o comportamento específico da fase de adolescência, com abordagem imparcial para o desenvolvimento de uma relação positiva, oportunizando descobrir seus próprios sentimentos e atitudes com relação à maternidade.

"Minha mãe, minha sogra que tá comigo, meu marido também ajuda, minhas cunhadas. Mas, não tenho com que conversar, prefiro guardar as coisas pra mim mesmo". Falta de dinheiro é o que mais atrapalha assim, o resto não atrapalha. O dinheiro faz falta e não tem como conseguí"(D1- 15 anos).

"Minha mãe me ajuda, ela me ensina como cuida, sabe lidá com essas coisas assim"(D2-16 anos).

Entre as puérperas não adolescentes percebe-se a indicação da mãe como apoio suportivo mais significativo, as vezes o pai ou irmão da puérpera. O apoio situa-se na dimensão física, sendo pouco enfatizada a dimensão emocional na fase de adaptação ao novo papel. Assim, é possível inferir que a falta de apoio suportivo emocional é deficiente por parte da família, tanto para as adolescentes, como para as mães não adolescentes.

"Meu pai, sempre que eu preciso de alguma coisa ele faz, leva no lugar que eu preciso ir. A minha mãe sempre que o bebê está chorando ela vai me ajudar a trocar. Meu irmão, quando está em casa, faz comida para mim, me ajuda a cuidar dela, também fica com ela para eu dormir" (D5-20 anos).

"Minha mãe me ajuda, ela ajuda a dar banho na bebê, cuida da roupa, da minha casa" D6-20 anos).

"Tem a minha irmã e tem uma vizinha lá, que eu trato ela de vó, sabe. Eu considero ela como uma mãe, por causa que eu não tenho pai nem mãe e, ela dá o maior apoio pra mim, assim, sabe. Ela é como uma mãe, cuida de mim, às vezes falta as coisas em casa, ela vem a traz, né. Sempre ela tá como uma mãe do meu lado" D1035 anos).

"O pai do bebê é bem atencioso, graças a Deus, eu tenho muito apoio. Tive durante toda a gestação e agora também. A minha sogra me ajuda, até tô na casa dela, por enquanto, assim, né, ajuda na limpeza, na alimentação. Tem bastante pessoas me ajudando assim" D12- 22 anos).

A terceira categoria "dificuldades que a transição suscita" fez emergir através dos depoimentos, as dificuldades que permeiam a transição à maternidade, sendo variadas sob diferentes enfoques, de acordo com a experiência e modo de vida de cada ser envolvido.

Entre as adolescentes, é possível perceber as instabilidades financeira, falta de condições para oferecer maior conforto ao bebê, precariedade de moradia, bem como as dificuldades de ordem emocional, como o medo do futuro. Dificuldades sociais e econômicas são comuns entre as mães adolescentes, as quais podem contribuir negativamente no alcance ao papel materno. Uma forte rede de suporte social, suporte da família e a preparação, antecipando a transição, são estratégias que causam grande impacto para a adaptação ao papel materno.

O suporte social inclui recursos emocionais, materiais, informações e suporte financeiro, estabelecido através do relacionamento interpessoal recíproco. MCVEIGH e SMITH (2000), enfatizam que as mães adolescentes que recebem suporte do com- 
panheiro, tendo maior envolvimento, interagem mais facilmente com seu bebê. Existe uma correlação negativa significante entre auto-estima, ansiedade e depressão pósparto. O período pós-parto é um período de redescobertas, reconstrução do próprio eu e a auto-estima que emerge frente ao papel materno, pode ser desafiada durante este período crítico de tempo.

"Falta de dinheiro é o que mais atrapalha assim, o resto não atrapalha. $O$ dinheiro faz falta e não tem como conseguí"(D1- 15 anos).

Cuidar do filho envolve muitas tarefas, as quais são realizadas de acordo com a personalidade e experiência da mãe. Muitas pedem ajuda e instruções, outras desejam resolver sozinhas as dificuldades, julgando assim construir fundamentos mais sólidos de sua competência como mãe. Portanto, o enfermeiro deve dedicar especial atenção a esse período, utilizando medidas simples de abordagem domiciliar ou ambulatorial, pois as ações de cuidado dispensadas, podem representar a diferença entre uma gravidez, parto e puerpério bem sucedidos e um evento transicional traumático na vida da mulher e família.

\section{CONSIDERAÇÕES FINAIS}

Todas as ações de cuidado neste período devem estar dirigidas para a superação de dificuldades, as quais são detectadas ao desempenhar o cuidado, através da aproximação, da perspicácia e habilidade na observação e percepção de indicativos da instabilidade que a transição suscita. Somente o contato interpessoal entre profissional e cliente pode oferecer os instrumentos para a efetivação do cuidado humanizado a esta situação peculiar e especial.

$O$ cuidado de enfermagem no período pós-parto tem por meta oferecer estratégias de enfrentamento e adaptação à transição à maternidade, através da rede de suporte profissional, em que muitas informações são importantes e necessitam ser repassadas em um curto espaço de tempo, durante a internação ou quando de seu re- torno para a consulta de enfermagem puerperal. Estes encontros entre enfermeiro e cliente/família, devem levar em consideração as mudanças ocorridas com a gestação e a readaptação ao estado não gravídico. É importante salientar as diferenças existentes para as mesmas experiências e expectativas entre adolescentes e não adolescentes. O tipo e a natureza do suporte recebido nessa fase pós-parto são fatores que podem contribuir negativa ou positivamente para a melhor adaptação e alcance do papel materno, pois se depara com as necessidades de suporte esperadas e as reais após o nascimento. Assim, durante o prénatal o enfermeiro necessita avaliar a autoestima, a rede de suporte social e a satisfação das futuras mães, para que após o parto, tenha o suporte necessário e disponível para enfrentar as mudanças e necessidades em sua vida.

A vivência no puerpério, da transição ao papel materno, exige a operacionalização do cuidado humano transicional, o qual auxilia a mulher a movimentar-se dentro da transição com maior autonomia e desprendimento para captar, enfrentar e adaptar-se ao novo papel. Somente alcança a transição quando ocorre a adaptação. Porém, esse processo nem sempre é tão simples e rápido, impõe a utilização de recursos internos e externos, disponíveis ou não pela mulher, para ultrapassar os obstáculos e barreiras que parecem intransponíveis, se realizado de maneira solitária. $O$ apoio suportivo é essencial, em que o enfermeiro, ao conhecer a situação vivenciada, auxilia à puérpera a superar mais facilmente, pela localização correta das pessoas que podem oferecer esse suporte.

A utilização do referencial teórico sobre transição e da metodologia de pesquisacuidado estabelece os caminhos metodológicos de implementação de novos modelos de cuidado humano, que privilegiem a mudança de papéis. Essa trajetória necessita ser utilizada pelos enfermeiros em diferentes contextos de atuação para firmar-se como estratégia de cuidado, pois ao mesmo tempo em que cuida, a pesquisa está sendo efetivada. Somente com os resultados de 
pesquisa é possível avaliar a resolubilidade do cuidado, compreender a dimensão vivenciada pelas puérperas adolescentes ou não, captar o verdadeiro sentido da experiência, estabelecer intercâmbio entre os profissionais e desenvolver uma relação interpessoal empática e de confiança.

\section{REFERÊNCIAS BIBLIOGRÁFICAS}

ARRUDA, E.N.; ZAGONEL, I.P.S. Pesquisa-cuidado como uma abordagem filosófica para o desenvolvimento do conhecimento de enfermagem. Texto Contexto Enfermagem. v.6, n.3, p.161-176, 1997.

BRANDEN, P.S. Enfermagem maternoinfantil. 2.ed. São Paulo : Reichmann \& Affonso Editores, 2000. p. 411-443.

DAL SASSO, G.T.M. A crise como uma oportunidade de crescimento para a família que enfrenta uma doença aguda : um desafio para a enfermagem.1994. Dissertação (Mestrado) Programa de Pós-Graduação em Enfermagem, Universidade Federal de Santa Catarina, Florianópolis.

EDWARDS, L.D. Adaptação à paternidade/maternidade. In: LOWDERMILK, D.L.; PERRY, S.E.; BOBAK, I.M. O cuidado em enfermagem materna. 5.ed. Porto Alegre : Artmed, 2002. p. 457495.

EIZIRIK, C.L.; KAPCZINSKI, F.; BASSOLS, A.M.S. (Org). O ciclo da vida humana: uma perspective psicodinâmica. Porto Alegre : Artmed, 2001.

LEONARD, V.W. A heideggerian phenomenologic perspective on the concept of the person. Advances in Nursing Sciences. v.11, n.4, p.40-55, 1989.

KONIAK - GRIFFIN, D. Maternal role attainment. Image : Journal of Nursing Scholarship. v.25, n.3, p.257-262, 1993.

MCVEIGH, C.; SMITH, M. A comparison of adult and teenage mother's self-esteem and satisfaction with social support. Midwifery. v.16, n.4. p.269-276, 2000.

STETSON, B. Avaliação e cuidado no quarto trimestre. In : LOWDERMILK, D.L.; PERRY, S.E.; BOBAK, I.M. O cuidado em enfermagem materna. 5.ed. Porto Alegre : Artmed, 2002. p. 424-456. 